\title{
Decúbito como fator agravante da cefaleia na crise migranosa
}

\author{
Juliana P. Macci', Carolina P. Jabarra', Mayara C. M. Teles', Gustavo de F. Ferreira', \\ Jano Alves De Souza' ${ }^{2}$, Pedro Ferreira Moreira Filho ${ }^{3}$ \\ 'Médico residente em Neurologia; ${ }^{2}$ Professor adjunto II de Neurologia da UFF; ${ }^{3}$ Professor associado IV da UFF \\ Setor de Investigação de Cefaleia da Universidade Federal Fluminense (UFF). Niterói, RJ, Brasil \\ Macci JP, Jabarra CP, Teles MC, Ferreira GF, De Souza JA, Moreira Filho PF. Decúbito como fator agravante \\ da cefaleia na crise migranosa. Headache Medicine. 2012;3(4):208-9
}

\section{INTRODUÇÃO}

As crises de migrânea são frequentemente incapacitantes. A atividade física e os movimentos de abaixar a cabeça são fatores reconhecidos de aumento transitório da intensidade da dor durante as crises. Por esse motivo, muitos pacientes buscam o repouso. Na prática clínica, verifica-se que uma parcela de pacientes se queixa de agravamento da cefaleia pelo decúbito, durante as crises de migrânea, preferindo permanecer na posição recos- 
tada ou sentada. Esse dado, até onde sabemos, não foi estudado.

\section{OBJETIVOS}

Verificar, numa amostra de pacientes migranosos, a porcentagem daqueles que se queixam de agravamento da cefaleia, durante a crise, pelo decúbito. Avaliar se existem diferenças com relação à piora pelo decúbito entre os sexos.

\section{METODOLOGIA}

Estudo retrospectivo de análise de prontuários. Foram avaliados os dados da anamnese de 734 pacientes consecutivos, com queixa principal de cefaleia, atendidos numa clínica terciária, desde que se passou a utilizar o programa HIPATIA (tutorial e banco de dados em cefaleias). Utilizando-se de filtros de pesquisa, foram selecionados os pacientes que receberam o diagnóstico de migrânea em qualquer de suas modalidades (1.1 a 1.6 da Classificação da IHS 2004) num total de 563 (76,7\%). Todos os pacientes foram interrogados quanto a fatores de agravamento da cefaleia, no período da crise, entre eles, o decúbito. Os que afirmaram apresentar agravamento pelo decúbito foram contabilizados e divididos de acordo com o gênero.

\section{RESULTADOS}

Dos 563 pacientes (482 mulheres - 85,6\%; 81 homens - 14,4\%) com diagnóstico de migrânea, 20,8\% ( $n=117$ ) queixaram-se de agravamento pelo decúbito. Destes, $89,7 \%(n=105)$ eram mulheres e $10,3 \%$ eram homens $(n=12)$.

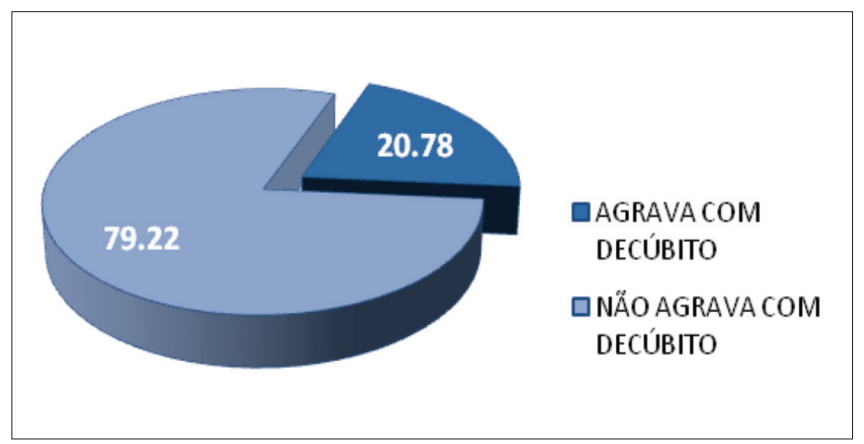

Gráfico 1 - Porcentagem dos pacientes com migrânea que se queixaram de agravamento da cefaleia pelo decúbito

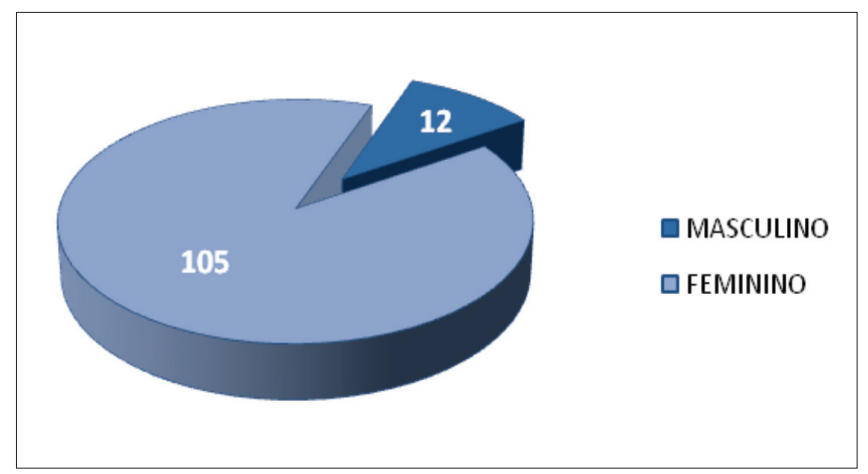

Gráfico 2 - Distribuição por gênero dentre os pacientes que se queixaram de agravamento da cefaleia pelo decúbito

\section{CONCLUSÃO}

O agravamento da cefaleia pelo decúbito é mais frequente no sexo feminino, assim como a migrânea. Acreditamos que o aumento do retorno venoso no decúbito e consequentemente da pressão de pulso seja possivelmente um dos responsáveis pelo agravamento da cefaleia pelo decúbito.

\section{REFERÊNCIAS}

1.Subcomitê de Classificação das Cefaléias da Sociedade Internacional de Cefaléia. Classificação Internacional das Cefaléias. 2.Ed. Trad. Sociedade Brasileira de Cefaléia. São Paulo: Segmento Farma Editores, 2004.

2. Lerusalimschy R.; Moreira Filho PF. Fatores desencadeadores de crises de migrânea em pacientes com migrânea sem aura.Arq Neuropsiquiatr. 2002;60(3-A):609-13.

3. Hung Cl, Liu CY, Wang SJ.Precipitating or aggravating factors for headache in patients with major depressive disorder. J Psychosom Res. 2008;64(2):231-5

4. Spierings EL, Ranke AH, Honkoop PC. Precipitating and aggravating factrs of migraine versus tension-type headaches. Headache. 2001;41(6):554-8. 